\title{
Magnetron Sputtered NbN Films with Nb Interlayer on Mild Steel
}

\author{
Kulwant Singh, ${ }^{1}$ A. C. Bidaye, ${ }^{2}$ and A. K. Suri ${ }^{3}$ \\ ${ }^{1}$ FRMS, MG, Bhabha Atomic Research Centre, Trombay, Mumbai 400085, India \\ ${ }^{2}$ SES, MPD, Bhabha Atomic Research Centre, Trombay, Mumbai 400085, India \\ ${ }^{3}$ Materials Group, Bhabha Atomic Research Centre, Trombay, Mumbai 400085, India \\ Correspondence should be addressed to Kulwant Singh, singhkw@barc.gov.in \\ Received 16 March 2011; Revised 1 July 2011; Accepted 1 July 2011 \\ Academic Editor: Ravin Kumar Dayal
}

Copyright (๑) 2011 Kulwant Singh et al. This is an open access article distributed under the Creative Commons Attribution License, which permits unrestricted use, distribution, and reproduction in any medium, provided the original work is properly cited.

The aim of the study is to extend the $\mathrm{NbN}$ coating on MS with $\mathrm{Nb}$ interlayer to explore the benefits of hard nitride coatings on low-cost structural material and to compare the coating with NbN monolithic coating on SS. NbN on MS and SS was deposited by reactive d.c. magnetron sputtering at various $\mathrm{N}_{2} / \mathrm{Ar}$ flow ratios and substrate bias. Deposition rate decreased from 20 to $10 \mathrm{~nm} / \mathrm{min}$ (without biasing) and from 16 to $8 \mathrm{~nm} / \mathrm{min}$ ( $-50 \mathrm{~V}$ biasing) when $F_{\mathrm{N}_{2}} / F_{\mathrm{Ar}}$ ratio was varied from zero to $70 \%$. Deposition rate decreased with the increase in bias voltage. Coatings showed hexagonal $\beta \mathrm{Nb}_{2} \mathrm{~N}$, cubic $\delta$ NbN, and hexagonal $\delta^{\prime} \mathrm{NbN}$ as major phases with the increasing $\mathrm{N}_{2}$ flow. Surface hardness reached a maximum of $2040 \mathrm{HK}_{25}$ at a $F_{\mathrm{N}_{2}} / F_{\mathrm{Ar}}$ of $20 \%$. Critical loads, for cohesive and adhesive failure for coating on MS, were between 6-8 N and 9-12 N respectively; for coating on SS, the values were between 7-15 N and 12-25 N respectively. Duplex coatings were studied for hardness by Knoop microindentation, adhesion by scratch tester, and corrosion by potentiodynamic polarization technique. Hardness, adhesion, and corrosion resistance all improved when $\mathrm{NbN}$ coating was incorporated with $\mathrm{Nb}$ interlayer on MS.

\section{Introduction}

Thin films of binary, ternary, and multicomponent nitride coatings, multilayers, duplex, and nanocrystalline coatings are widely deposited by magnetron sputtering [1-5]. Hard nitride coatings find commercial applications in various industries. TiN, CrN, TiAlN, and so forth have evinced a lot of interest as wear-resistant, protective coatings. Advances in deposition techniques have focused interest in developing novel coating alternatives. Niobium nitride $(\mathrm{NbN})$ films have been investigated primarily for their superconducting properties rather than their mechanical properties. The research for synthesis of $\mathrm{NbN}$ film was directed to increase its superconducting transition temperatures [6-8]. However, these are suitable for wear-resistant, protective coatings too. $\mathrm{NbN}$ possess good mechanical properties coupled with wear resistance, chemical inertness, high melting point, high temperature stability, and high electrical conductivity, which make $\mathrm{NbN}$ films a suitable material for protective coating [9], field emission cathode [10], and diffusion barrier in microelectronic devices [11]. NbN films have been deposited by various techniques, which include reactive magnetron sputtering [12-15], ion beam deposition [16, 17], pulsed laser deposition [18], and cathodic arc deposition [1922]. In superlattice coatings also, $\mathrm{NbN}$ finds use as onelayer component. Superlattice coatings such as $\mathrm{TiN} / \mathrm{NbN}$ [23-25], TaN/NbN [26], and CrN/NbN [27, 28] have been investigated for use as hard, wear-resistant, and corrosionprotective coatings. Superlattice films possess superhardness effects, which exhibit an anomalous increase in hardness and wear resistance.

Mild steel (MS) is widely used as a structural material due to its low cost. Properties of mild steel such as hardness, wear resistance, and corrosion resistance are not adequate. Application of hard nitride coatings on mild steel can modify the surface of mild steel necessary for practical applications. Hard nitride coatings deposited by physical vapor deposition (PVD) techniques exhibit high hardness, good wear resistance, and excellent chemical inertness. However, corrosion behavior of these coatings is often insufficient because of the presence of pin-hole porosity and microcracks inherent in PVD coatings. The corrosive media can attack the steel through these pores and microcracks. Various interlayers have been used to address the problem $[29,30]$. NbN 
coatings with interlayer, however, have not been investigated much. Duplex coatings involving TiN top coat, deposited by sputtering, with interlayer of chromium $(\mathrm{Cr})$ or nickel (Ni) deposited by electroplating and electroless nickel (EN) deposited by electroless technique have been studied to explore the benefits of hard nitride coatings on cheaper mild steel (MS) substrates [29-33]. These duplex coatings were found to improve the hardness, corrosion resistance, and other properties when extended on to MS substrates.

The aim of the present study is to propose a prospective coating combination on mild steel for versatile application. In the present study, $\mathrm{NbN}$ coatings have been extended on to MS substrate with niobium $(\mathrm{Nb})$ interlayer deposited by sputtering and the results have been compared with the monolithic $\mathrm{NbN}$ coating on SS. For this $\mathrm{NbN}$, coatings were deposited on MS and stainless steel (SS) substrates. Coatings were studied for their thickness, structure, hardness, and adhesion. Process parameters were optimized, and then, $\mathrm{NbN}$ coating with $\mathrm{Nb}$ interlayer was deposited on to MS substrate. These duplex coatings were studied for the improvement with respect to adhesion by scratch tests, surface hardness by Knoop microindentation, and corrosion performance by potentiodynamic polarization technique. Open circuit potentials were also measured.

\section{Experimental Procedure}

$\mathrm{NbN}$ films were deposited using reactive DC magnetron sputtering on SS-, MS-, and Nb-coated MS substrates. An Nb (99.99\% purity) metallic target, $160 \mathrm{~mm}$ diameter and $4 \mathrm{~mm}$ thick, was mechanically clamped to a planar sputter source mounted horizontally on the base of the chamber evacuated to a base pressure of $2 \times 10^{-6}$ mbar. The distance between the target and the substrate was $60 \mathrm{~mm}$. The sputtering pressure was kept at $5 \times 10^{-3}$ mbar by admitting a stream of mixed gas of argon (Ar) and nitrogen $\left(\mathrm{N}_{2}\right)$ into the chamber. Flow of Ar gas was fixed at $20 \mathrm{sccm}$, while $\mathrm{N}_{2}$ flow was varied from $0-14 \mathrm{sccm}$. Substrate biasing was kept constant at $-50 \mathrm{~V}$ for coatings deposited at different $\mathrm{N}_{2} / \mathrm{Ar}$ flow ratios. Coatings were deposited without externally heating the substrate. The power to the target was supplied through a stabilized d. c. power supply of 0-1000 V (6 Amperes maximum). Substrate biasing was varied from 0 to $-150 \mathrm{~V}$ in a step of $25 \mathrm{~V}$ (keeping the $\mathrm{N}_{2}$ /Ar flow ratio constant at $20 \%$ ) by means of a stabilized $\mathrm{d}$. c. power supply of variable voltage $(0-300 \mathrm{~V})$ and current $(0-500 \mathrm{~mA})$. The samples were polished, cleaned thoroughly, and degreased in alkaline solution prior to deposition. The flow sheet used for the cleaning of the substrate samples is presented in the Figure 1. All the cleaning steps were performed ultrasonically for the specified duration. The MS samples were also deposited with $\mathrm{Nb}$ interlayer and $\mathrm{NbN}$ as top coatings. The deposition parameters for $\mathrm{Nb}$ and $\mathrm{NbN}$ coatings were similar (Table 1) except that no $\mathrm{N}_{2}$ was introduced for the $\mathrm{Nb}$ coating. Substrate biasing for $\mathrm{Nb}$ deposition was kept at $-50 \mathrm{~V}$. Thickness of $\mathrm{Nb}$ interlayer was $2 \mu \mathrm{m}$.

Weight gain of the samples was recorded and thickness of the coatings was calculated using bulk density values. Actual coating thicknesses were studied by microabrasion using

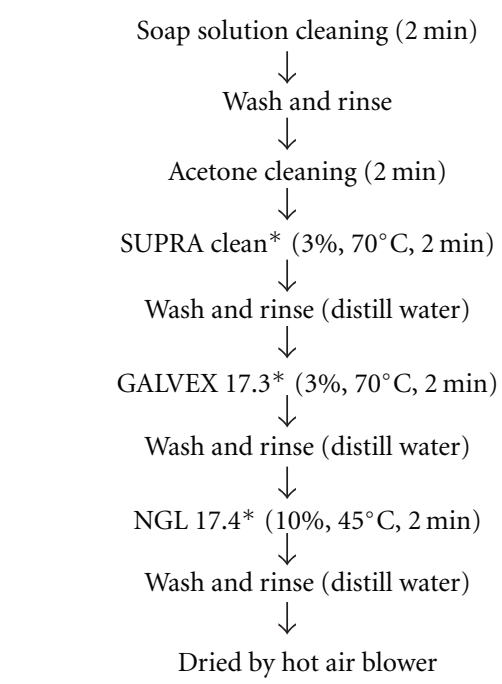

* Alkali-based cleaning mixture from NGL technology

Figure 1: As used cleaning cycle.

TABLE 1: Deposition parameters for $\mathrm{Nb}$ and $\mathrm{NbN}$ coatings.

\begin{tabular}{lc}
\hline Parameter & Value \\
\hline Base pressure & $2 \times 10^{-6} \mathrm{mbar}$ \\
Operating pressure & $5 \times 10^{-3} \mathrm{mbar}$ \\
Argon gas flow rate & $20 \mathrm{sccm}$ \\
Nitrogen gas flow rate & $0-14 \mathrm{sccm}$ \\
Substrate biasing & 0 to $-150 \mathrm{~V}$ \\
Target current $\mathrm{NbN} / \mathrm{Nb}$ & $0.25 / 0.3 \mathrm{Ampere}$ \\
Target-substrate distance & $\sim 60 \mathrm{~mm}$ \\
\hline
\end{tabular}

Calotest technique. In Calotest, an AISI 52100 hardened chrome steel ball (hardness $=65 \mathrm{HRC}$ ) is rotated against the coated specimen using the diamond particles suspended in a fluid. Roughness of the bare and coated samples was measured by a contact type diamond stylus profilometer. The phase structure of the films was investigated by X-ray diffraction (XRD) with $\mathrm{CuK}_{\alpha}$ radiation. Diffraction study was carried out for a $2 \theta$ range of $20-90^{\circ}$. Since the majority of the coating peaks were found to be in the $2 \theta$ range of $30-60^{\circ}$, evaluation of duplex coating is shown in the $2 \theta$ range of $30-60^{\circ}$. Surface hardness was measured by a microhardness tester (Future Tech FM-7 model) using Knoop indenter at the load of 25 gf. Five readings were performed for each sample and the average values are reported. Adhesion of the coatings was evaluated by scratch adhesion tester at different loading rates of $10,30,50$, and $80 \mathrm{~N} / \mathrm{min}$; since the effect of loading rate was very limited, loading rate for further scratch tests was restricted to $30 \mathrm{~N} / \mathrm{min}$. The scratch length was kept constant at $4 \mathrm{~mm}$ for all the scratch tests. The scratch indenter used was a $200 \mu \mathrm{m}$ tip radius Rockwell-type diamond indenter. Friction force and depth of indentation for all the scratched samples were recorded online. The scratch tracks were seen in the optical microscopy immediately after the tests to visualize the scratch patterns, and pictures were taken at different loads. 
Tests were performed in a linearly progressive mode from $1 \mathrm{~N}$ start load to a predefined maximum load. The maximum load was varied from $10 \mathrm{~N}$ to $60 \mathrm{~N}$. The results displayed are for the maximum load of $40 \mathrm{~N}$, since the coatings were found to delaminate beyond this load.

Electrochemical evaluation of the coated samples was carried out using the standard potentiodynamic measurement technique with a computer controlled Santronic Electrochemical Analyzer. Tests were carried out using a threeelectrode cell. Coated samples were soldered (with indium) to a copper wire coated with enamel. The samples were masked by Shailmask 800 lacquer (proprietary) to get the $1 \mathrm{~cm}^{2}$ surface area exposed. All potentials were measured with respect to a saturated calomel electrode (SCE). The auxiliary or counter electrode was platinum. The anodic and cathodic electrochemical polarization curves of all the samples were obtained in $\mathrm{N}_{2}$ de-aerated $1 \mathrm{~N} \mathrm{H}_{2} \mathrm{SO}_{4}$ electrolyte at room temperature. Open circuit potentials (OCPs) were measured in deaerated $1 \mathrm{~N} \mathrm{H}_{2} \mathrm{SO}_{4}$ solution for 2 hrs. Before potentiodynamic measurements, the samples were allowed to reach equilibrium potential $\left(E_{\text {ocp }}\right)$. This potential was reached after 30-40 minutes, and the electrochemical measurements were started when the potential did not change by more than $1 \mathrm{mV} / \mathrm{min}$. The solution was replaced after each sweep run. Polarization resistance was determined in the $\pm 15 \mathrm{mV}$ domain of $E_{\text {ocp }}$ potential using the linear polarization method at a scan rate of $0.1 \mathrm{mV} / \mathrm{sec}$. For potentiodynamic studies, a potential sweep range of $-1.000 \mathrm{~V}$ to $+1.000 \mathrm{~V}$ was applied with a scan rate of $0.5 \mathrm{mV} / \mathrm{sec}$. The plot of $E$ measured against SCE v/s $\log I$ was plotted. The corrosion potential $\left(E_{\text {corr }}\right)$ was determined from the intersection of Tafel slopes and the corrosion current density $\left(I_{\text {corr }}\right)$ was calculated using the anodic and cathodic Tafel slopes $\left(\beta_{a}\right.$ and $\left.\beta_{c}\right)$ and polarization resistance $\left(R_{p}\right)$.

\section{Results and Discussion}

3.1. Thickness. A variation of $5 \%-10 \%$ in the thickness of the coatings was found between the calculated values (weight gain method) and the actual values (Calotest technique). This was due to the density of the coatings being lower than the bulk values. In the deposition using biasing, there was a continuous ion bombardment at the substrate, which reduced the effective deposition rate. Therefore, more time was required to get the same coating thickness for coatings deposited at higher bias voltages. NbN coating thicknesses of $1.8 \mu \mathrm{m} \pm 10 \%$ was obtained for coatings deposited at various parameters. Thickness of $\mathrm{Nb}$ interlayer was $2 \mu \mathrm{m}$. Total coating thickness on the MS substrate with interlayer was about $4 \mu \mathrm{m}$.

\subsection{Deposition Rate}

3.2.1. Effect of Nitrogen Flow. Deposition rate of $\mathrm{Nb}-\mathrm{N}$ coatings as a function of $\mathrm{N}_{2} / \mathrm{Ar}$ flow ratio has been plotted in Figure 2. The coatings were deposited without substrate bias and at a constant substrate bias voltage of $-50 \mathrm{~V}$. Deposition rate of $\mathrm{Nb}-\mathrm{N}$ films varied with the variation in

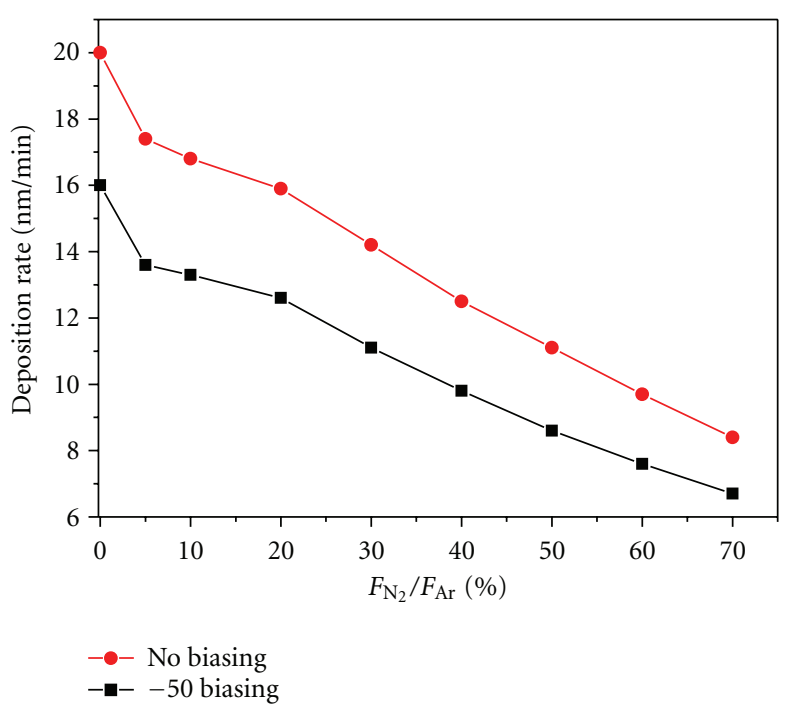

FIGURE 2: Deposition rate of Nb-N coatings versus $F_{\mathrm{N}_{2}} / F_{\mathrm{Ar}}\left(F_{\mathrm{Ar}}=\right.$ $20 \mathrm{sccm}$ fixed).

$\mathrm{N}_{2} /$ Ar flow ratio. Deposition rate decreased from $20 \mathrm{~nm} / \mathrm{min}$ to $10 \mathrm{~nm} / \mathrm{min}$ (without biasing) and from $16 \mathrm{~nm} / \mathrm{min}$ to $8 \mathrm{~nm} / \mathrm{min}$ (with biasing at $-50 \mathrm{~V}$ ) with the increase in $\mathrm{N}_{2} / \mathrm{Ar}$ flow ratio from $0 \%$ to $70 \%$. Deposition rate reduced almost linearly in both the cases with every increase in $\mathrm{N}_{2}$ flow. The decrease in deposition rate, with every increase in nitrogen flow, was due to the increased nitridation of the target well known as the poisoning of the target surface. Further, it was seen that the reduction in deposition rate followed three different linear paths in both the cases-with biasing or without biasing. Transition in linearity in deposition rates was due to the transition in phases as revealed by X-ray diffraction (Section 3.3). The transition in deposition rates corresponded to the transition of phases from $\mathrm{Nb}$ to $\beta-\mathrm{Nb}_{2} \mathrm{~N}$, $\beta-\mathrm{Nb}_{2} \mathrm{~N}$ to cubic $\delta-\mathrm{NbN}$, and cubic $\delta-\mathrm{NbN}$ to hexagonal $\delta^{\prime}-$ $\mathrm{NbN}$.

3.2.2. Effect of Substrate Biasing. Figure 3 shows the deposition rate plotted against the substrate bias voltage keeping the $\mathrm{N}_{2}$ /Ar flow ratio constant at $20 \%$. It was observed that deposition rate decreased with the increase in substrate biasing (negative) voltage. The deposition rate decreased from 15.9 to $6.0 \mathrm{~nm} / \mathrm{min}$ when the bias voltage was increased from zero to $-150 \mathrm{~V}$ in a step of $25 \mathrm{~V}$. The decrease in deposition rate with the increase in substrate biasing was due to the resputtering effect at the substrate. With every increase in substrate biasing (negative voltage) increased resputtering at the substrate with higher energy ions takes place. This causes removal of entrapped gas atoms, densification of the grain boundaries, and resputtering of depositing particles, resulting in fall of deposition rates. Increased ion bombardment improves adhesion, hardness, and density of the coatings.

3.3. X-Ray Diffraction. X-ray diffraction patterns of $\mathrm{Nb}-\mathrm{N}$ films deposited on SS at various $\mathrm{N}_{2} /$ Ar flow ratios are shown in Figure 4. Coatings deposited at $5 \%$ of $\mathrm{N}_{2} / \mathrm{Ar}$ flow ratio 


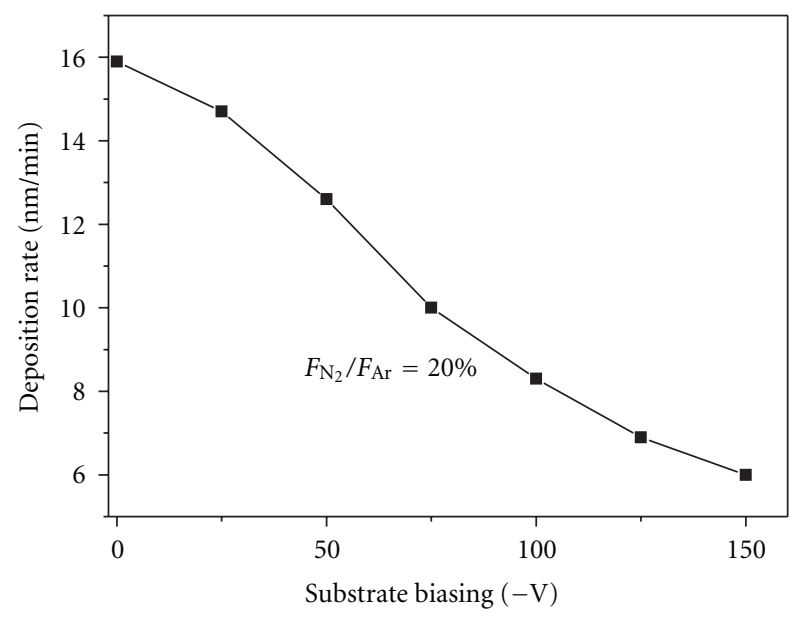

FIGURE 3: Deposition rate of Nb-N coating versus substrate biasing $\left(F_{\mathrm{N}_{2}} / F_{\mathrm{Ar}}=20 \%\right)$.

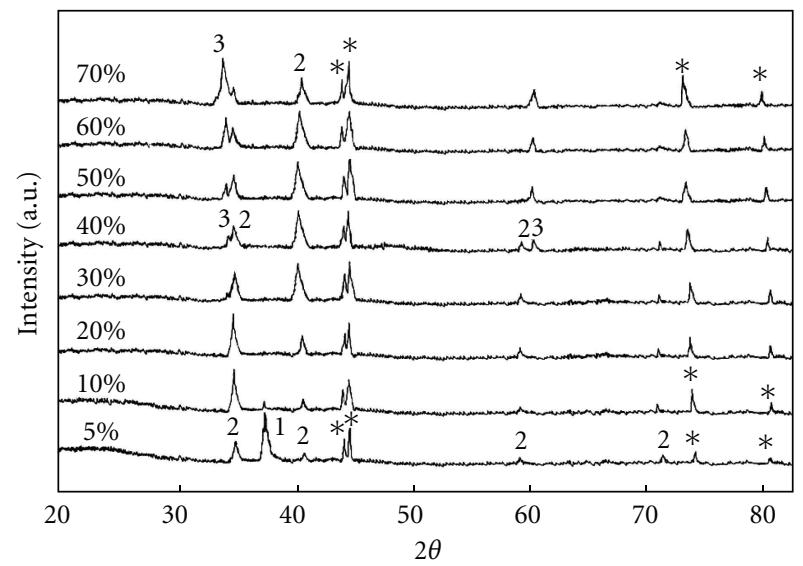

$\begin{array}{ll}\text { (1) } \mathrm{Nb}_{2} \mathrm{~N} & \text { (3) } \delta^{\prime} \mathrm{NbN} \\ \text { (2) } \delta \mathrm{NbN} & * \text { Substrate }\end{array}$

FIGURE 4: X-ray diffraction patterns of Nb-N Coatings on SS deposited at $5 \%-70 \%$ of $F_{\mathrm{N}_{2}} / F_{\mathrm{Ar}}$ (substrate bias was fixed at $-50 \mathrm{~V}$ ).

showed hexagonal $\beta-\mathrm{Nb}_{2} \mathrm{~N}$ as the major phase with (101) preferred orientation. With the increase in $\mathrm{N}_{2} / \mathrm{Ar}$ flow ratio to $10 \%$, the major phase became cubic $\delta$-NbN with preferred orientation of (111). At $30 \% \mathrm{~N}_{2} / \mathrm{Ar}$ flow ratio hexagonal $\delta^{\prime}$ $\mathrm{NbN}$ phase appeared though the major phase was still cubic $\delta$-NbN but now with preferred orientation of (200). With the further increase in $\mathrm{N}_{2} / \mathrm{Ar}$ flow ratio, the hexagonal $\delta^{\prime}$ $\mathrm{NbN}$ phase increased and became major phase at $70 \% \mathrm{~N}_{2}$ flow. In all the coatings, substrate peaks were identified as the stronger peaks.

Figure 5 shows the X-ray diffraction patterns of $\mathrm{Nb}$ and $\mathrm{NbN}$ with $\mathrm{Nb}$ interlayer on MS substrate; $\mathrm{NbN}$ coatings were deposited at $\mathrm{N}_{2} /$ Ar flow ratio of $20 \%$. $\mathrm{Nb}$ (110) was found to be stronger than $\mathrm{Nb}$ (200) peak. The intensity of $\mathrm{Nb}$ peaks reduced when $\mathrm{NbN}$ top coat was given. MS sample showed the peak of $\mathrm{Fe}(110)$ in the $2 \theta$ range performed. $\mathrm{NbN}$ (111) peak was found to be stronger than $\mathrm{NbN}$ (200) or NbN (220) peaks.

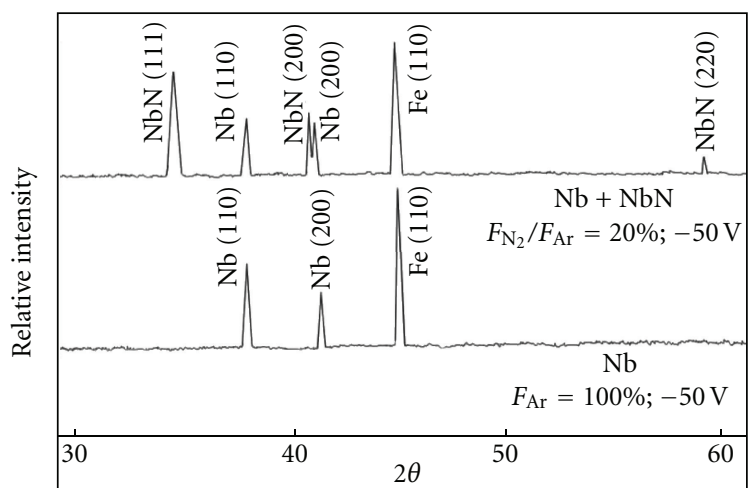

Figure 5: X-ray diffraction patterns of $\mathrm{Nb} / \mathrm{MS}$ and $\mathrm{NbN} / \mathrm{Nb} / \mathrm{MS}$ $\left(\mathrm{Nb}\right.$ and $\mathrm{NbN}$ coatings were deposited in pure Ar and $F_{\mathrm{N}_{2}} / F_{\mathrm{Ar}}=$ $20 \%$, respectively; biasing was $-50 \mathrm{~V}$ for both).

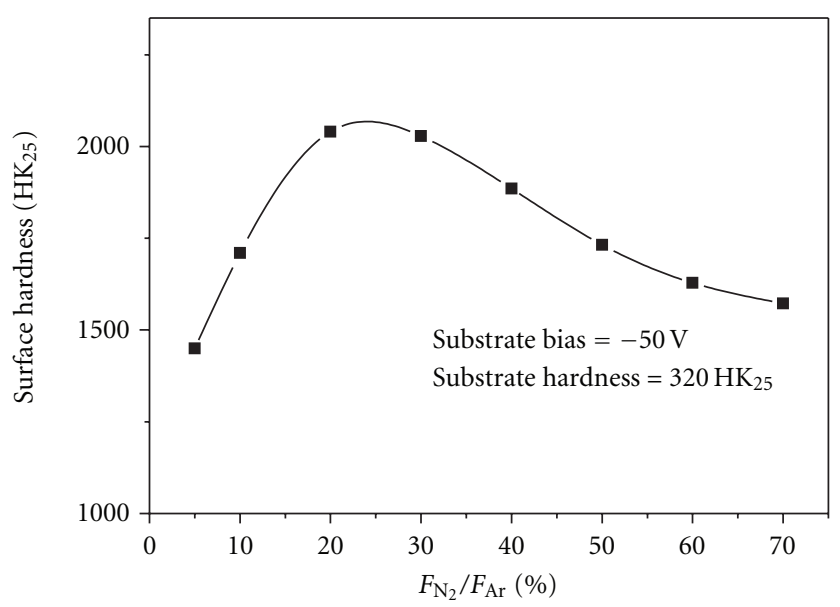

FIGURE 6: Surface hardness (at $25 \mathrm{gf}$ ) of $\mathrm{Nb}-\mathrm{N}$ coatings deposited on SS substrate at various $F_{\mathrm{N}_{2}} / F_{\mathrm{Ar}}\left(F_{\mathrm{Ar}}=20 \mathrm{sccm}\right.$; substrate bias = $-50 \mathrm{~V})$.

\subsection{Hardness}

3.4.1. Effect of Nitrogen Flow. Knoop microhardness values for Nb-N coatings on SS, taken at a load of $25 \mathrm{gf}$, have been plotted as a function of $\mathrm{N}_{2} / \mathrm{Ar}$ flow ratio in Figure 6 (substrate bias was kept constant at $-50 \mathrm{~V}$ ). Knoop hardness of the uncoated SS substrate was $320 \mathrm{HK}$ at a load of $25 \mathrm{gf}$. Surface hardness was found to increase rapidly with the increase in $\mathrm{N}_{2} / \mathrm{Ar}$ flow ratio. The surface hardness reached a maximum of $2040 \mathrm{HK}_{25}$ at a $\mathrm{N}_{2} / \mathrm{Ar}$ flow ratio of $20 \%$ and then started decreasing slowly with the further increase in $\mathrm{N}_{2}$ flow. The decrease in hardness was accompanied with the observed changes in the crystalline structure of coatings, as revealed by XRD discussed in Section 3.3. Since, the maximum hardness obtained was at $20 \%$ of $\mathrm{N}_{2}$ /Ar flow ratio, deposition of $\mathrm{NbN}$ coating with $\mathrm{Nb}$ interlayer on $\mathrm{MS}$ was carried out at $20 \%$ of $\mathrm{N}_{2} / \mathrm{Ar}$ flow ratio. For Knoop hardness at $25 \mathrm{gf}$, depth of indentation varied between 0.44 and $0.52 \mu \mathrm{m}$. As a thumb rule, the depth of the indentation should be 8-10 times less than the thickness of the coating to reflect the true hardness of the films without the effect of the base substrate. Otherwise, plastic deformation occurs in 


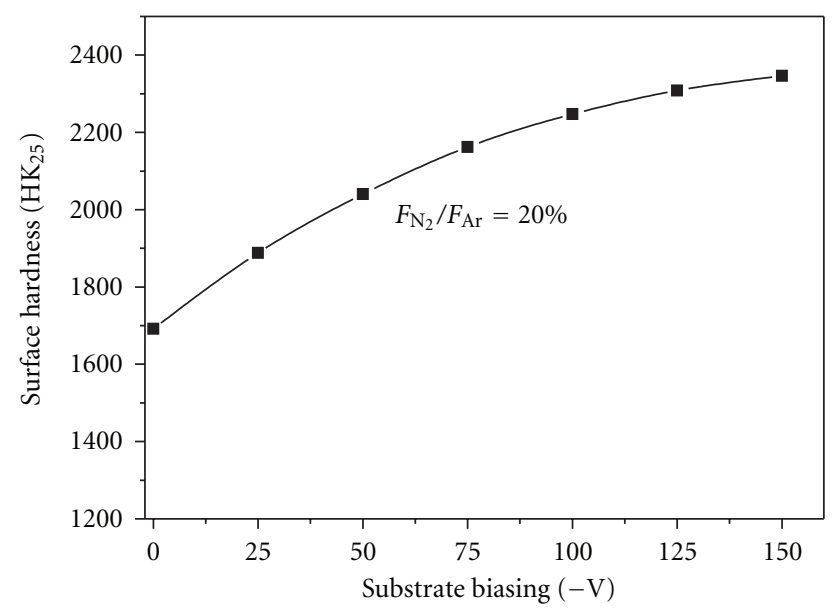

Figure 7: Surface hardness (at $25 \mathrm{gf}$ ) of Nb-N coatings on SS (deposited at $F_{\mathrm{N}_{2}} / F_{\mathrm{Ar}}=20 \%$ ) versus substrate biasing.

the softer substrate such as steel. Lichinchi et al. [34] have shown by means of finite element method (FEM) modeling that indentation into TiN on high-speed steel (HSS) causes plastic deformation in the substrate when the indentation depth reaches $15 \%$.

To get the true hardness of the $\mathrm{NbN}$ coating, a coating thickness of about $4 \mu \mathrm{m}$ was required. However, in the present study, the coating thickness was $\leq 2 \mu \mathrm{m}$; therefore, the hardness values obtained show the composite hardness of the substrate-coating combination and not the true hardness of the films.

Grain size also influences the hardness of the materials. Hardness changes as per the Hall-Petch relationship. Grain size has been found to increase with the increase in the partial pressure of nitrogen [35-37]. The decrease in hardness at higher partial pressures of nitrogen could also be attributed partly due to the increase in grain sizes.

Roughness of the coated samples was found to replicate the values of the polished surface $(0.06-0.08 \mu \mathrm{m})$, and no difference in the roughness of the samples was observed after the coatings. Therefore, roughness of the coating does not seem to play a role in the hardness effects observed in the present study.

3.4.2. Effect of Substrate Biasing. Figure 7 shows the surface hardness of $\mathrm{NbN}$ coatings at $25 \mathrm{gf}$ deposited at various substrate bias voltages, keeping the $\mathrm{N}_{2}$ /Ar flow ratio constant at $20 \%$. Hardness increased continuously with the increase in substrate bias voltage. Hardness increased from $1692 \mathrm{HK}_{25}$ for coatings deposited without biasing to $2346 \mathrm{HK}_{25}$ for coatings deposited at $-150 \mathrm{~V}$ substrate biasing. Kim et al. [38] observed the increase in hardness similarly with the increase in substrate bias voltage up to $-200 \mathrm{~V}$. The hardness enhancement by energetic ion bombardment is due to a complex, synergistic effect involving a decrease of crystallite size, densification of the grain boundaries, formation of radiation damage and other point defects, and built-in biaxial compressive stress [39].
TABLE 2: Surface hardness of MS, and $\mathrm{Nb}, \mathrm{NbN}$, and duplex coatings on MS.

\begin{tabular}{lc}
\hline Coating & Hardness $\left(\mathrm{HK}_{25}\right)$ \\
\hline Substrate $(\mathrm{MS})$ & 198 \\
$\mathrm{Nb}$ & 434 \\
$\mathrm{NbN}$ & 1084 \\
$\mathrm{Nb}+\mathrm{NbN}$ & 1436 \\
\hline
\end{tabular}

The development of the morphology and microstructure of sputtered films bombarded by energetic ions during their growth is described by the Thornton diagram [40]. It is well known that ion bombardment due to biasing (the substrate) generally causes a reduction in the grain size $[40,41]$. The increased ion flux with higher kinetic energy provides increased ion bombardment on the growing film, which leads to a reduction in the grain size. Hardness increases with the refinement of grain structure.

Hardness is found correlated directly to the compressive stresses also. Researchers have reported similar enhancement of the hardness and compressive stress for a variety of hard coatings deposited by magnetron sputtering [42] and vacuum arc evaporation [43].

3.4.3. Duplex Coatings on MS. The surface hardness of MS substrate, $\mathrm{Nb}, \mathrm{NbN}$, and duplex coating of $\mathrm{NbN}$ with $\mathrm{Nb}$ interlayer on MS are given in Table 2. Hardness values obtained show the composite hardness of the substratecoating combination. With the incorporation of $\mathrm{Nb}$ interlayer, the surface hardness of $\mathrm{NbN}$ coating increased from $1084 \mathrm{HK}_{25}$ to $1436 \mathrm{HK}_{25}$ due to the load support provided by the interlayer.

3.5. Scratch Adhesion Test. Friction force and depth of indentation for all the scratch tests were recorded online along with the indenter movement to confirm the critical loads for cracks, chipping, delamination, coating failure, or other such observations. Tests performed at different loading rates were observed to give almost similar results, and variation in loading rate had little impact; therefore, loading rate for scratch tests was kept at $30 \mathrm{~N} / \mathrm{min}$.

Several types of observations were revealed as the scratch progressed, such as upper mono layers removal, pile-up on the sides, visibility of small cracks to long wide cracks within the coatings, pores, chipping, and partial or complete delamination of the coating. Figure 8 shows the scratch patterns for $\mathrm{NbN}$ coating on $\mathrm{MS}$ sample; at $9 \mathrm{~N}$ load, the scratch pattern showed the chipping and cracks at few places, while at $28 \mathrm{~N}$ load, the coating was delaminated almost completely.

Figure 9 exhibits the scratch patterns for $\mathrm{NbN}$ coating on SS taken at various loads. Start of the scratch is shown at $1 \mathrm{~N}$ load; at $12 \mathrm{~N}$ load, segregation, cracks within coating and pores were visible though coating was still intact; at $22 \mathrm{~N}$ load, along with cracks, pores, chipping, and delamination at few places occurred; at $32 \mathrm{~N}$ load, coating was found to delaminate at many places. The coatings showed much better 


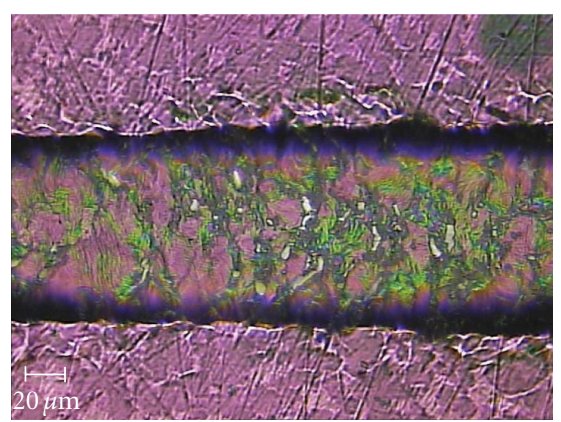

(a)

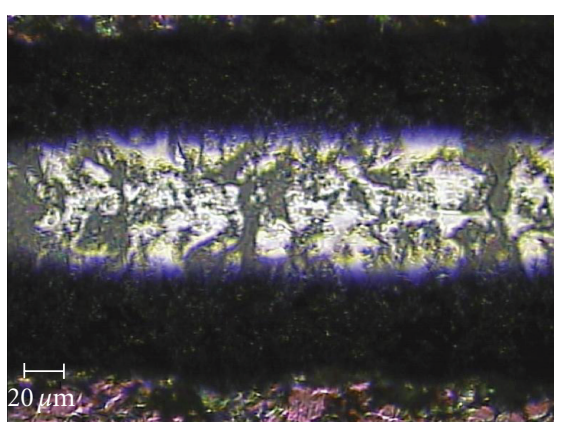

(b)

FIGURE 8: Scratch test for $\mathrm{NbN}$ coating (deposited at $\mathrm{N}_{2} / \mathrm{Ar}$ flow $=20 \%$ ) on MS at (a) $9 \mathrm{~N}$ load, showing chipping and cracks and (b) $28 \mathrm{~N}$ load, showing nearly complete delamination.

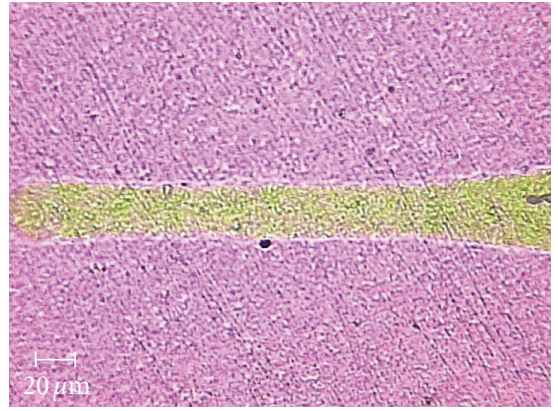

(a)

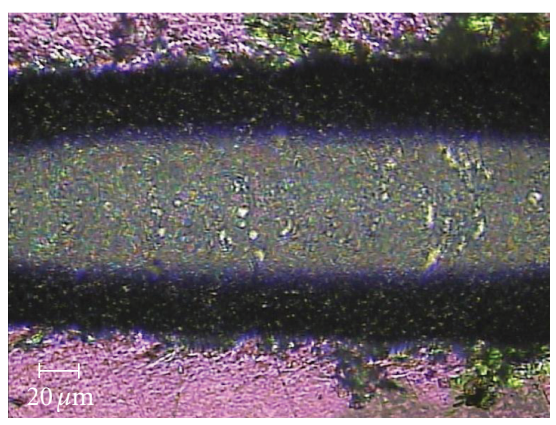

(c)

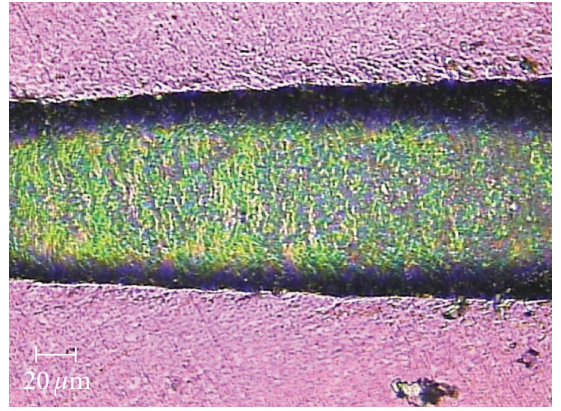

(b)

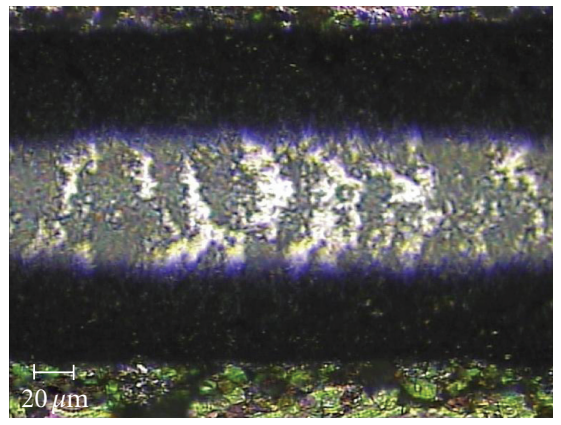

(d)

Figure 9: Scratch test for $\mathrm{NbN}$ coating (deposited at $\mathrm{N}_{2} / \mathrm{Ar}$ flow $=20 \%$ ) on $\mathrm{SS}$ at (a) $1 \mathrm{~N}$, showing start of the scratch, (b) $12 \mathrm{~N}$, revealing segregation, cracks and pores, (c) $22 \mathrm{~N}$ displaying chipping, cracks, pores, pile-up, and (d) $32 \mathrm{~N}$, showing chipping, cracks, pores, pile-up, and delamination.

performance on SS samples than on MS samples. However, when $\mathrm{NbN}$ coated MS sample with Nb interlayer was scratchtested (Figure 10), it performed equally or even better than $\mathrm{NbN}$ coating on SS. Comparing the scratch patterns of $\mathrm{NbN} / \mathrm{SS}$ (Figure 9) and NbN/Nb/MS (Figure 10) at the same loads reveal less damage for $\mathrm{NbN}$ coatings with $\mathrm{Nb}$ interlayer with respect to chipping, cracks, pores, and delamination.

3.5.1. Critical Loads. Two critical loads, $\mathrm{Lc}_{1}$ and $\mathrm{Lc}_{2}$, have been defined for the failure of the coatings. $\mathrm{Lc}_{1}$, the first critical load, corresponds to initial cohesive failure of the coating such as appearance of first cracks within the coating. $\mathrm{Lc}_{2}$, the second critical load, corresponds to initial adhesive failure of the coating, that is, first observation of adhesive failure such as chipping, partial delamination, pores, or some such phenomena, where substrate beneath coating gets exposed. $\mathrm{Lc}_{1}$ and $\mathrm{Lc}_{2}$ for coating on MS samples were observed to be between 6-8 $\mathrm{N}$ and 9-12 $\mathrm{N}$ loads, respectively. For coatings deposited on SS substrates $\mathrm{Lc}_{1}$ varied between $7-15 \mathrm{~N}$ and $\mathrm{Lc}_{2}$ between $12-25 \mathrm{~N}$. NbN coatings on SS showed better performance than $\mathrm{NbN}$ coatings on MS. However, for $\mathrm{Nb}$ interlayered $\mathrm{NbN}$ coatings on $\mathrm{MS}$, the critical loads improved; $\mathrm{Lc}_{1}$ was found to be between 8$14 \mathrm{~N}$ and $\mathrm{Lc}_{2}$ between $10-24 \mathrm{~N}$, showing almost equal or sometimes slightly better performance than $\mathrm{NbN}$ coatings on SS. 


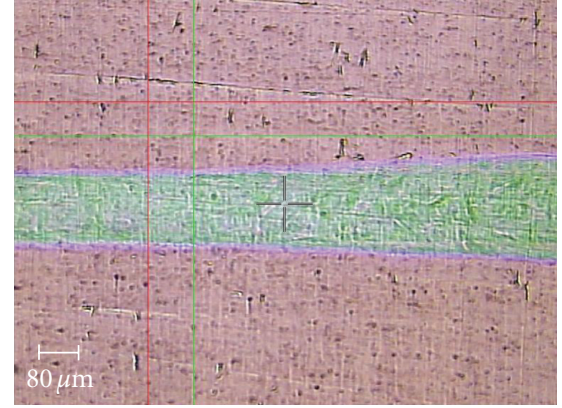

(a)

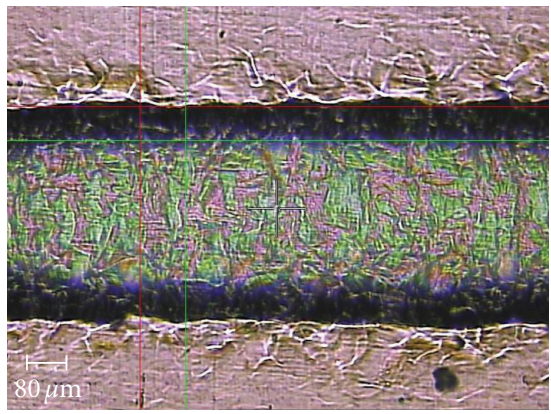

(c)

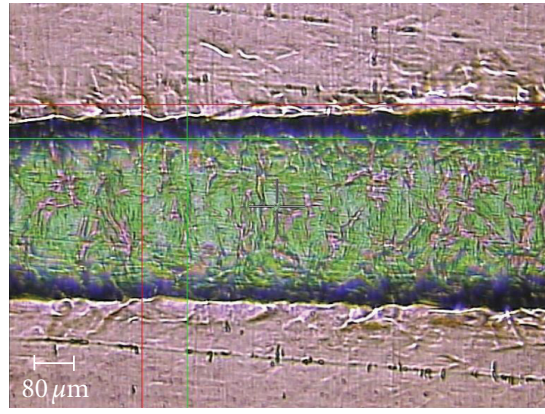

(b)

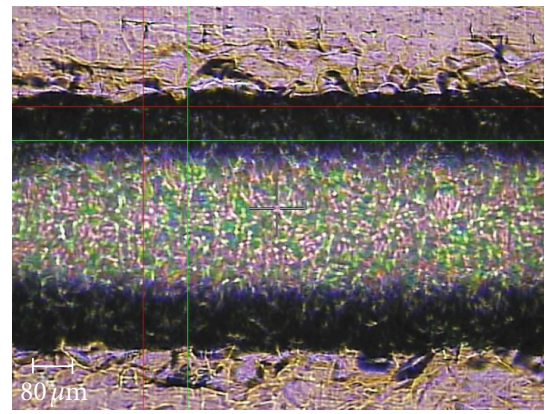

(d)

Figure 10: Scratch test for NbN coating (deposited at $\mathrm{N}_{2} /$ Ar flow $=20 \%$ ) on MS with Nb interlayer at (a) $1 \mathrm{~N}$, showing start of the scratch, (b) $12 \mathrm{~N}$, revealing segregation, cracks, and pores, (c) $22 \mathrm{~N}$, displaying cracks, pores, and pile-up, and (d) $32 \mathrm{~N}$, showing chipping, pile-up, and partial delamination.

TABLE 3: $\mu$ at different loads for NbN/MS, NbN/SS and NbN/Nb/ MS, during scratch tests.

\begin{tabular}{lccc}
\hline \multirow{2}{*}{ Load $(\mathrm{N})$} & \multicolumn{3}{c}{ Coefficient of friction $(\mu)$} \\
& MS & SS & Nb/MS \\
\hline 20 & 0.23 & 0.20 & 0.18 \\
30 & 0.28 & 0.25 & 0.24 \\
40 & 0.35 & 0.30 & 0.30 \\
60 & 0.45 & 0.40 & 0.38 \\
\hline
\end{tabular}

3.5.2. Coefficient of Friction. Coefficient of friction $(\mu)$, as observed in the scratch adhesion test, increased with the increase in scratch load. $\mu$ represents the value for coatingsubstrate combination. $\mathrm{NbN}$ coating, being hard, expected to show lower $\mu$ value, while MS substrate is expected to show higher $\mu$ value. The increase in the $\mu$ value with the increase in scratch load was due to the increasing effect from the substrates. For coatings deposited on SS samples, the value was found to vary within a narrow range of $0.22-0.25$ at $30 \mathrm{~N}$ load irrespective of coatings deposited at different $\mathrm{N}_{2}$ /Ar flow ratios. At $60 \mathrm{~N}$, load the value increased to 0.40 . Table 3 lists the $\mu$ value at different loads for the two types of substrates along with $\mathrm{Nb}$ interlayered $\mathrm{NbN}$ coating on MS substrate. NbN coating on MS samples showed higher coefficient of friction than on SS samples at the same applied scratch loads. However, with $\mathrm{Nb}$ interlayer, the $\mu$ decreased to $0.24,0.30$, and 0.38 at 30,40 , and $60 \mathrm{~N}$ loads, respectively, thus clearly demonstrating the improvement in $\mu$ value for $\mathrm{Nb}$ interlayered $\mathrm{NbN}$ coatings.
3.5.3. Depth of Penetration. Depth of penetration increased with the increase in applied load. At $30 \mathrm{~N}$ load, on an average, MS samples had 20-30 $\mu \mathrm{m}$ depth of penetration, while SS samples had $12-25 \mu \mathrm{m}$ depth of penetration. NbN coating on $\mathrm{MS}$ with $\mathrm{Nb}$ interlayer reduced the depth of penetration to $14-24 \mu \mathrm{m}$ at the same applied loads. Depth of penetration includes elastic as well as plastic deformation of the coating substrate combination during loading. Besides, there could be error factors such as natural slopes of the samples (thickness variation in sample) and mounting errors.

3.5.4. Effect of Loading Rate. The effect of loading rate was studied for NbN coatings on MS and SS substrates. The effect of loading rate on $\mathrm{Lc}_{1}$ and $\mathrm{Lc}_{2}$ was found to have little impact. The $\mathrm{Lc}_{1}$ value was found to shift from $7 \mathrm{~N}$ at $10 \mathrm{~N} / \mathrm{min}$ to $7.5 \mathrm{~N}$ at $30 \mathrm{~N} / \mathrm{min}$ and further to $8.2 \mathrm{~N}$ at $50 \mathrm{~N} / \mathrm{min}$. Similarly, $\mathrm{Lc}_{2}$ value shifted from $8.2 \mathrm{~N}$ to $9 \mathrm{~N}$ and further to $9.5 \mathrm{~N}$ with similar increase in applied loading rates.

For SS samples, the $\mathrm{Lc}_{1}$ changed from 15 to $17 \mathrm{~N}$ and $\mathrm{Lc}_{2}$ changed from $22 \mathrm{~N}$ to $24 \mathrm{~N}$ when the applied loading rate was increased successively from $20 \mathrm{~N} / \mathrm{min}$ to $80 \mathrm{~N} / \mathrm{min}$.

3.5.5. Effect of Biasing. Effect of biasing was studied on $\mathrm{NbN}$ coated SS samples. Increase in biasing voltage from zero to $-75 \mathrm{~V}$ (in a step of $25 \mathrm{~V}$ ), keeping other factors constant, led to successive increase in the values of $\mathrm{Lc}_{1}$ and $\mathrm{Lc}_{2}$. At $-75 \mathrm{~V}$, biasing the $\mathrm{Lc}_{1}$ and $\mathrm{Lc}_{2}$ values was found to be $15.6 \mathrm{~N}$ and $26 \mathrm{~N}$, respectively. However, at $-100 \mathrm{~V}$, the coating became brittle, and $\mathrm{Lc}_{1}$ and $\mathrm{Lc}_{2}$ values dropped drastically to 7 and 
TABLE 4: Effect of biasing on critical loads during scratch tests for $\mathrm{NbN}$ coatings on SS.

\begin{tabular}{lcc}
\hline Biasing $(-\mathrm{V})$ & $\mathrm{Lc}_{1}(\mathrm{~N})$ & $\mathrm{Lc}_{2}(\mathrm{~N})$ \\
\hline 0 & 6.5 & 10.5 \\
25 & 10.5 & 20 \\
50 & 12.0 & 24 \\
75 & 15.6 & 26 \\
100 & 7.0 & 11 \\
\hline
\end{tabular}

TABLE 5: Effect of $\mathrm{N}_{2}$ flow on critical loads during scratch tests for $\mathrm{NbN}$ coatings on SS.

\begin{tabular}{lcc}
\hline$F_{\mathrm{N}_{2}} / F_{\mathrm{Ar}}(\%)$ & $\mathrm{Lc}_{1}(\mathrm{~N})$ & $\mathrm{Lc}_{2}(\mathrm{~N})$ \\
\hline 10 & 11 & 18 \\
20 & 12 & 24 \\
30 & 11 & 25 \\
40 & 10 & 20 \\
50 & 8 & 20 \\
60 & 8 & 18 \\
70 & 7 & 14 \\
\hline
\end{tabular}

$11 \mathrm{~N}$, respectively. The values at various substrate biasing are shown in Table 4. Decreased adhesion of the films at higher bias is likely due to the greater stresses introduced into the film, as it is bombarded with more energetic ions $[44,45]$.

3.5.6. Effect of $\mathrm{N}_{2}$ Flow. Nb-N coatings on SS samples deposited at $\mathrm{N}_{2}$ /Ar flow ratio ranging from $10 \%$ to $70 \%$, (keeping the biasing voltage constant at $-50 \mathrm{~V}$ ) were tested for scratch adhesion. Results with respect to critical loads are shown in Table 5. Coatings deposited at $20 \%$ and $30 \%$ of $\mathrm{N}_{2}$ /Ar flow ratio showed better adhesion with higher critical loads showing $\mathrm{Lc}_{1}$ at 11-12 $\mathrm{N}$ and $\mathrm{Lc}_{2} 24-25 \mathrm{~N}$. $\mathrm{Lc}_{1}$ and $\mathrm{Lc}_{2}$ values decreased successively to $7 \mathrm{~N}$ and $14 \mathrm{~N}$ with the further increase in $\mathrm{N}_{2} / \mathrm{Ar}$ flow to $70 \%$. This could be attributed to more gaseous impurities, less dense structure, and the presence of pores in the coatings [40].

3.6. Corrosion Resistance. It is difficult to deposit the hard coatings by physical vapor deposition (PVD) techniques without any micro porosity. Thus, when a PVD coated sample is exposed to the corrosive environment, the electrochemical behavior of the coated sample is the combined behavior of the coating and the substrate. The polarization curve of such a specimen may be considered as a combination of two curves-one representing the base material and the other the coating.

3.6.1. Open Circuit Potential. Figure 11 shows the changes in open circuit potential (OCP) with immersion time for $\mathrm{NbN}$ and $\mathrm{NbN}$ with $\mathrm{Nb}$ interlayer coated on $\mathrm{MS}$ sample. For $\mathrm{NbN}$ coating, potential decreased from an initial value of -252 to $-478 \mathrm{mV}$ in $30 \mathrm{~min}$ and to $-498 \mathrm{mV}$ in $40 \mathrm{~min}$ after which it remained nearly constant indicating the establishment of equilibrium between metal and the solution.

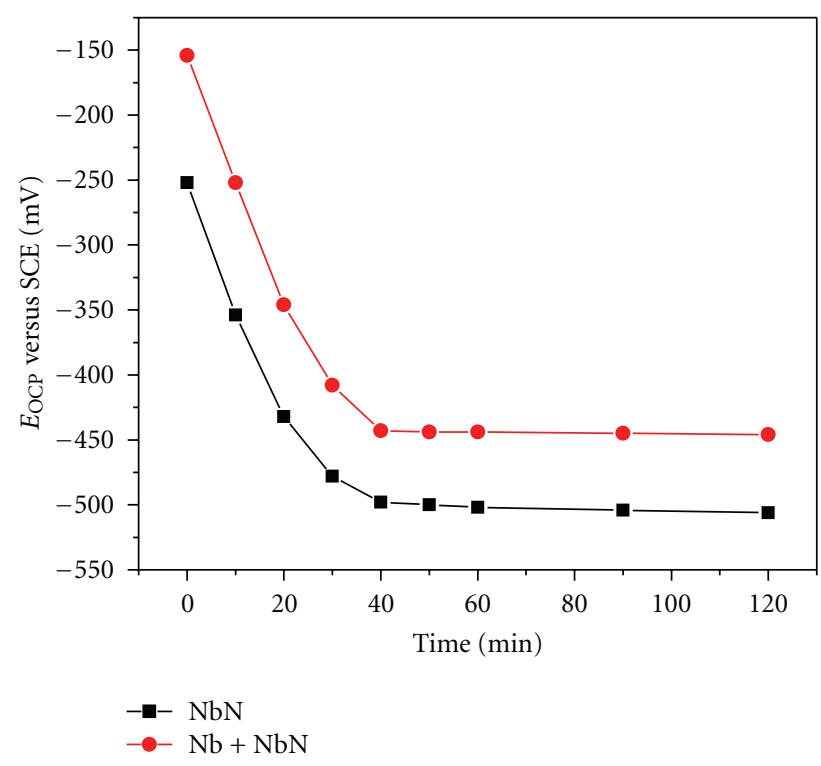

Figure 11: $E_{\mathrm{OCP}}$ versus time for $\mathrm{NbN} / \mathrm{MS}$ with and without $\mathrm{Nb}$ interlayer in $1 \mathrm{~N} \mathrm{H}_{2} \mathrm{SO}_{4}$.

TABLE 6: $E_{\text {corr }}$ and $I_{\text {corr }}$ values for single and duplex coatings on MS.

\begin{tabular}{lcc}
\hline Coating & $E_{\text {corr }}(\mathrm{mV})$ & $I_{\text {corr }}\left(\mu \mathrm{A} / \mathrm{cm}^{2}\right)$ \\
\hline Substrate & -496.4 & 1440.3 \\
$\mathrm{NbN}$ & -412.1 & 150.2 \\
$\mathrm{Nb}$ & -469.3 & 121.8 \\
$\mathrm{Nb}+\mathrm{NbN}$ & -396.2 & 14.8 \\
\hline
\end{tabular}

The equilibrium value was found to be quite similar to MS substrate without coating, thus indicating the presence of pores in the coating, resulting in corrosion taking place beneath $\mathrm{NbN}$ coating. For $\mathrm{NbN}$ coatings on MS substrate with $\mathrm{Nb}$ interlayer, the OCP shifted to $-154 \mathrm{mV}$ in the beginning from $-252 \mathrm{mV}$ for coating without interlayer. The value decreased to about $-443 \mathrm{mV}$ after $40 \mathrm{~min}$ and remained constant thereafter.

3.6.2. Potentiodynamic Tests. A high $E_{\text {corr }}$ and a low $I_{\text {corr }}$ values are indicative of good corrosion resistance. Table 6 lists the $E_{\text {corr }}$ and $I_{\text {corr }}$ values for MS substrate: $\mathrm{NbN}, \mathrm{Nb}$, and $\mathrm{NbN}$ coating with $\mathrm{Nb}$ interlayer on MS substrate. Plain MS substrate had $E_{\text {corr }}$ value of $-496.4 \mathrm{mV}$ and $I_{\text {corr }}$ value of $1440 \mu \mathrm{A} / \mathrm{cm}^{2}$. Coating the MS sample with $\mathrm{NbN}$ improved the corrosion resistance by decreasing the corrosion current ( $\left.I_{\text {corr }}\right)$ to $150 \mu \mathrm{A} / \mathrm{cm}^{2}$ and increasing the $E_{\text {corr }}$ (less negative) to $-412 \mathrm{mV}$. However, the improvement was constrained due to the presence of pin-hole porosity inherent in PVD coatings. Due to the presence of pin-hole defects in the $\mathrm{NbN}$ coatings, rapid pitting corrosion of MS substrate takes place at these defects; even leading to partial debonding of the coating during the tests. The potentiodynamic curves for $\mathrm{NbN}$ coatings, therefore, mimic the behavior of MS substrate.

$\mathrm{Nb}$ interlayer was found to improve the corrosion resistance of $\mathrm{NbN}$ coated $\mathrm{MS}$ substrates effectively. For $\mathrm{Nb}$ 


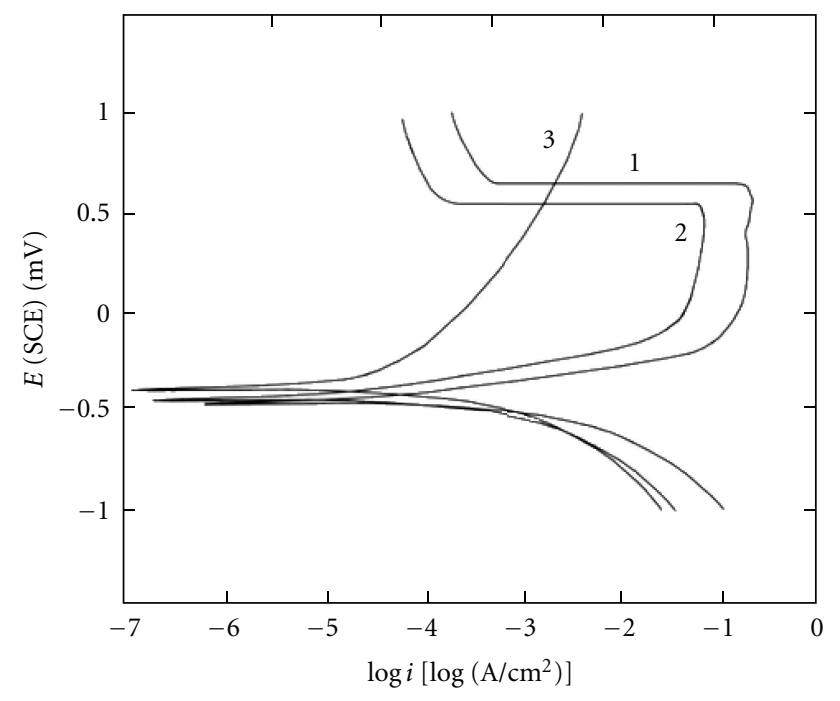

(1) Substrate

(2) $\mathrm{NbN}$

(3) $\mathrm{Nb}+\mathrm{NbN}$

Figure 12: Potentiodynamic curves for MS, NbN/MS and NbN/ $\mathrm{Nb} / \mathrm{MS}$.

interlayered $\mathrm{NbN}$ coating, $E_{\text {corr }}$ and $I_{\text {corr }}$ was found to be $-396.2 \mathrm{mV}$ and $14.8 \mu \mathrm{A} / \mathrm{cm}^{2}$, respectively. With the duplex coating, the adherence also improved, because duplex coating did not delaminate for the full potential sweep of $-1000 \mathrm{mV}$ to $+1000 \mathrm{mV}$ during the potentiodynamic corrosion test. Potentiodnamic curves for substrate, $\mathrm{NbN}$ coating, and $\mathrm{NbN}$ coating with $\mathrm{Nb}$ interlayer on MS substrates are shown in Figure 12. Potentiodynamic curve for the duplex coatings showed a remarkable improvement in corrosion improvement for MS substrate. In general, it was observed that the duplex coating is much superior to $\mathrm{NbN}$ coatings alone.

\section{Conclusions}

$\mathrm{NbN}$ coatings were deposited on MS and SS substrates by reactive DC magnetron sputtering. $F_{\mathrm{N}_{2}} / F_{\mathrm{Ar}}$ was varied from $0 \%$ to $70 \%$ and substrate biasing from zero to $-150 \mathrm{~V}$ in a step of $25 \mathrm{~V}$. Coatings were characterized for their thickness by weight gain and Calotest technique, hardness by Knoop microhardness tester, phase analysis by X-ray diffraction technique, and adhesion by scratch adhesion tester. The effect of $\mathrm{N}_{2}$ flow and substrate biasing was evaluated. After the optimization of process parameters, NbN coatings were deposited on MS substrate with $2 \mu \mathrm{m}$ thick $\mathrm{Nb}$ interlayer. Effect of interlayer on $\mathrm{NbN}$ coating on MS substrate was studied for the improvements in surface hardness by Knoop microindentation, adhesion by scratch test, and corrosion by potentiodynamic polarization technique in $1 \mathrm{~N} \mathrm{H}_{2} \mathrm{SO}_{4}$ solution at room temperature. Open circuit potentials were also measured. The following conclusions were drawn.

Deposition rate decreased from 20 to $10 \mathrm{~nm} / \mathrm{min}$ (without biasing) and from 16 to $8 \mathrm{~nm} / \mathrm{min}$ (with biasing at $-50 \mathrm{~V}$ ) with the increase in $\mathrm{N}_{2}$ flow from $0 \%$ to $70 \%$. Deposition rate decreased from 15.9 to $6 \mathrm{~nm} / \mathrm{min}$ when the bias voltage was increased from zero to $-150 \mathrm{~V}$ successively. Coatings showed presence of hexagonal $\beta \mathrm{Nb}_{2} \mathrm{~N}$, cubic $\delta \mathrm{NbN}$, and hexagonal $\delta^{\prime} \mathrm{NbN}$ as the major phases with increasing $\mathrm{N}_{2}$ flow.

Surface hardness on SS reached a maximum of $2040 \mathrm{HK}_{25}$ at a $\mathrm{N}_{2}$ /Ar flow ratio of $20 \%$ and then decreased slowly with the further increase in $\mathrm{N}_{2}$ /Ar flow ratio. Surface hardness increased from $1084 \mathrm{HK}_{25}$ to $1618 \mathrm{HK}_{25}$ when incorporated with $\mathrm{Nb}$ interlayer. Critical loads for cohesive $\left(\mathrm{Lc}_{1}\right)$ and adhesive $\left(\mathrm{Lc}_{2}\right)$ failures during scratch test for coatings on MS samples were observed to be between 6$8 \mathrm{~N}$ and 9-12 $\mathrm{N}$ loads, respectively; while for coatings on SS substrates, the values were between $7-15 \mathrm{~N}$ and $12-$ $25 \mathrm{~N}$, respectively. For duplex coating on MS, the values were between 8-14 and 10-24 N, respectively. Coefficient of friction $(\mu)$ during scratch test was $0.22-0.25$ at $30 \mathrm{~N}, 0.30$, at $40 \mathrm{~N}$ and 0.40 at $60 \mathrm{~N}$ loads for coatings deposited on SS samples. For coatings on MS sample, the $\mu$ was 0.28 at $30 \mathrm{~N}$, 0.35 at $40 \mathrm{~N}$, and 0.45 at $60 \mathrm{~N}$ loads. For $\mathrm{NbN}$ coating on MS with $\mathrm{Nb}$ interlayer, the $\mu$ was $0.24,0.30$ and 0.38 at 30,40 , and $60 \mathrm{~N}$ loads, respectively, demonstrating the improvement in $\mu$ value. Increase in loading rate had little impact on critical loads. Increase in substrate biasing up to $-75 \mathrm{~V}$ improved the $\mathrm{Lc}_{1}$ and $\mathrm{Lc}_{2}$ to 12 and $25 \mathrm{~N}$, respectively; further increase in substrate biasing caused the critical loads to decrease to 7 and $14 \mathrm{~N}$, respectively. Coatings deposited at $20 \%$ and $30 \% \mathrm{~N}_{2} / \mathrm{Ar}$ flow ratio showed better adhesion with higher critical loads showing $\mathrm{Lc}_{1}$ 11-12 $\mathrm{N}$ and $\mathrm{Lc}_{2} 24-25 \mathrm{~N}$.

Open circuit potential for $\mathrm{NbN}$ coated $\mathrm{MS}$ sample decreased from an initial value of $-252 \mathrm{mV}$ to $-478 \mathrm{mV}$ in $30 \mathrm{~min}$ and to $-498 \mathrm{mV}$ in $40 \mathrm{~min}$ after which it stabilized. The equilibrium value was found to be quite similar to MS substrate, thus indicating the presence of pores in the coating, resulting in corrosion taking place beneath coating. For duplex coating, OCP shifted to $-154 \mathrm{mV}$ in the beginning and stabilized to $-443 \mathrm{mV}$ after $40 \mathrm{~min}$. With duplex coating the corrosion resistance increased remarkably. $I_{\text {corr }}$ decreased from $150.2 \mu \mathrm{A} / \mathrm{cm}^{2}$ to $14.8 \mu \mathrm{A} / \mathrm{cm}^{2}$.

\section{References}

[1] J. Lin, J. J. Moore, W. D. Sproul, B. Mishra, Z. Wu, and J. Wang, "The structure and properties of chromium nitride coatings deposited using $\mathrm{dc}$, pulsed $\mathrm{dc}$ and modulated pulse power magnetron sputtering," Surface and Coatings Technology, vol. 204, no. 14, pp. 2230-2239, 2010.

[2] A. R. Shankar, B. P. Reddy, V. Chawla, M. J. Preyanga, R. Chandra, and U. K. Mudali, "Characterization of nitride coatings on high density graphite deposited by magnetron sputtering," Surface and Coatings Technology, vol. 204, no. 20, pp. 3214-3221, 2010.

[3] S. H. Mohamed, "Thermal stability of tungsten nitride films deposited by reactive magnetron sputtering," Surface and Coatings Technology, vol. 202, no. 10, pp. 2169-2175, 2008.

[4] H. C. Barshilia, B. Deepthi, and K. S. Rajam, "Growth and characterization of aluminum nitride coatings prepared by pulsed-direct current reactive unbalanced magnetron sputtering," Thin Solid Films, vol. 516, no. 12, pp. 4168-4174, 2008.

[5] X.-K. Du, T. -M. Wang, C. Wang, B.-L. Chen, and L. Zhou, "Microstructure and optical characterization of magnetron 
sputtered NbN thin films," Chinese Journal of Aeronautics, vol. 20, no. 2, pp. 140-144, 2007.

[6] W. N. Maung, D. P. Butler, and C. L. Huang, "Fabrication of $\mathrm{NbN}$ thin films by reactive sputtering," Journal of Vacuum Science \& Technology A, vol. 11, pp. 615-620, 1993.

[7] D. F. Dawson-Elli, C. A. Fung, and J. E. Nordman, "DC reactive magnetron sputtered $\mathrm{NbN}$ thin films prepared with and without hollow cathode enhancement," IEEE Transactions on Magnetics, vol. 27, no. 2, pp. 1592-1595, 1991.

[8] M. J. Deen, "The effect of the deposition rate on the properties of d.c.-magnetron-sputtered niobium nitride thin films," Thin Solid Films, vol. 152, no. 3, pp. 535-544, 1987.

[9] M. Benkahoul, E. Martinez, A. Karimi, R. Sanjinés, and F. Lévy, "Structural and mechanical properties of sputtered cubic and hexagonal NbNx thin films," Surface and Coatings Technology, vol. 180, pp. 178-183, 2004.

[10] Y. Gotoh, M. Nagao, T. Ura, H. Tsuji, and J. Ishikawa, "Ion beam assisted deposition of niobium nitride thin films for vacuum microelectronics devices," Nuclear Instruments and Methods in Physics Research B, vol. 148, no. 1-4, pp. 925-929, 1999.

[11] P. Alén, M. Ritala, K. Arstila, J. Keinonen, and M. Leskelä, "The growth and diffusion barrier properties of atomic layer deposited NbNx thin films," Thin Solid Films, vol. 491, no. 1-2, pp. 235-241, 2005.

[12] J. J. Olaya, S. E. Rodil, and S. Muhl, "Comparative study of niobium nitride coatings deposited by unbalanced and balanced magnetron sputtering," Thin Solid Films, vol. 516, no. 23, pp. 8319-8326, 2008.

[13] C. S. Sandu, M. Benkahoul, M. Parlinska-Wojtan, R. Sanjinés, and F. Lévy, "Morphological, structural and mechanical properties of $\mathrm{NbN}$ thin films deposited by reactive magnetron sputtering," Surface and Coatings Technology, vol. 200, no. 2223, pp. 6544-6548, 2006.

[14] M. Fenker, M. Balzer, and H. Kappl, "Corrosion behaviour of decorative and wear resistant coatings on steel deposited by reactive magnetron sputtering-tests and improvements," Thin Solid Films, vol. 515, no. 1, pp. 27-32, 2006.

[15] S. K. Kim, B. C. Cha, and J. S. Yoo, "Deposition of NbN thin films by DC magnetron sputtering process," Surface and Coatings Technology, vol. 177-178, pp. 434-440, 2004.

[16] M. L. Klingenberg and J. D. Demaree, "The effect of transport ration and ion energy on the mechanical properties of IBAD niobium nitride coatings," Surface and Coatings Technology, vol. 146-147, pp. 243-249, 2001.

[17] N. Hayashi, I. H. Murzin, I. Sakamoto, and M. Ohkubo, "Single-crystal niobium nitride thin films prepared with radical beam assisted deposition," Thin Solid Films, vol. 259, no. 2, pp. 146-149, 1995.

[18] G. Cappuccio, U. Gambardella, A. Morone, S. Orlando, and O. P. Parisi, "Pulsed laser ablation of $\mathrm{NbN} / \mathrm{MgO} / \mathrm{NbN}$ multilayers," Applied Surface Science, vol. 109, pp. 399-402, 1997.

[19] J. L. Mo and M. H. Zhu, "Tribological characterization of chromium nitride coating deposited by filtered cathodic vacuum arc," Applied Surface Science, vol. 255, no. 17, pp. 7627-7634, 2009.

[20] N. Cansever, M. Danişman, and K. Kazmanli, "The effect of nitrogen pressure on cathodic arc deposited NbN thin films," Surface and Coatings Technology, vol. 202, no. 24, pp. 59195923, 2008.

[21] N. Cansever, "Properties of niobium nitride coatings deposited by cathodic arc physical vapor deposition," Thin Solid Films, vol. 515, no. 7-8, pp. 3670-3674, 2007.
[22] A. Bendavid, P. J. Martin, T. J. Kinder, and E. W. Preston, “The deposition of $\mathrm{NbN}$ and $\mathrm{NbC}$ thin films by filtered vacuum cathodic arc deposition," Surface and Coatings Technology, vol. 163-164, pp. 347-352, 2003.

[23] H. C. Barshilia, K. S. Rajam, and D. V. Sridhara Rao, "Characterization of low temperature deposited nanolayered TiN/NbN multilayer coatings by cross-sectional transmission electron microscopy," Surface and Coatings Technology, vol. 200, no. 14-15, pp. 4586-4593, 2006.

[24] L. Geyang, H. Zenghu, T. Jiawan, X. Junhua, and G. Mingyuan, "Alternating stress field and superhardness effect in TiN/NbN superlattice films," Journal of Vacuum Science and Technology, Part A, vol. 20, no. 3, pp. 674-677, 2002.

[25] X. Chu, S. A. Barnett, M. S. Wong, and W. D. Sproul, "Reactive unbalanced magnetron sputter deposition of polycrystalline TiN/NbN superlattice coatings," Surface and Coatings Technology, vol. 57, no. 1, pp. 13-18, 1993.

[26] X. Junhua and L. Geyang, "Microstructure and mechanical properties of polycrystalline $\mathrm{NbN} / \mathrm{TaN}$ superlattice films," Journal of Materials Science, vol. 35, no. 14, p. 3535, 2000.

[27] Y. P. Purandare, M. M. Stack, and P. E. Hovsepian, "Velocity effects on erosion-corrosion of $\mathrm{CrN} / \mathrm{NbN}$ "superlattice" PVD coatings," Surface and Coatings Technology, vol. 201, no. 1-2, pp. 361-370, 2006.

[28] D. B. Lewis, S. J. Creasey, C. Wüstefeld, A. P. Ehiasarian, and P. E. Hovsepian, "The role of the growth defects on the corrosion resistance of CrN/NbN superlattice coatings deposited at low temperatures," Thin Solid Films, vol. 503, no. 1-2, pp. 143-148, 2006.

[29] J. S. Chen, J. G. Duh, and F. B. Wu, "Microhardness and corrosion behavior in $\mathrm{CrN}$ / electroless $\mathrm{Ni} /$ mild steel complex coating," Surface and Coatings Technology, vol. 150, no. 2-3, pp. 239-245, 2002.

[30] G. Li, P. Deshpande, J. H. Li, and R. Y. Lin, "Nano Cr interlayered CrN coatings on steels," Tsinghua Science and Technology, vol. 10, no. 6, pp. 690-698, 2005.

[31] V. K. W. Grips, V. Ezhil Selvi, H. C. Barshilia, and K. S. Rajam, "Effect of electroless nickel interlayer on the electrochemical behavior of single layer $\mathrm{CrN}$, TiN, TiAlN coatings and nanolayered TiAlN/CrN multilayer coatings prepared by reactive dc magnetron sputtering," Electrochimica Acta, vol. 51, no. 17, pp. 3461-3468, 2006.

[32] A. K. Graver, K. Singh, M. K. Totlani, and A. K. Suri, "TiN coatings on nickel and electroless nickel (EN) plated mild steel," Transactions of the Institute of Metal Finishing, vol. 78, no. 1, pp. 23-28, 2000.

[33] K. Singh, D. N. Wasnik, A. K. Graver, M. K. Totlani, and A. K. Suri, "TiN coatings modified by an interlayer of electroplated chromium on mild steel," Transactions of the Institute of Metal Finishing, vol. 77, no. pt 5, pp. 196-199, 1999.

[34] M. Lichinchi, C. Lenardi, J. Haupt, and R. Vitali, "Simulation of Berkovich nanoindentation experiments on thin films using finite element method," Thin Solid Films, vol. 312, no. 1-2, pp. 240-248, 1998.

[35] L.-J. Meng and M. P. Dos Santos, "Characterization of titanium nitride films prepared by d.c. reactive magnetron sputtering at different nitrogen pressures," Surface and Coatings Technology, vol. 90, no. 1-2, pp. 64-70, 1997.

[36] M. Cekada, P. Panjan, M. Maček, and P. Šmíd, "Comparison of structural and chemical properties of Cr-based hard coatings," Surface and Coatings Technology, vol. 151-152, pp. 31-35, 2002.

[37] R. Wuhrer and W. Y. Yeung, "An empirical analysis of nitrogen pressure effect on grain size development of nanostructured 
ternary nitride coatings," Materials Forum, vol. 29, pp. 103107, 2005.

[38] S. K. Kim, B. C. Cha, and J. S. Yoo, "Deposition of NbN thin films by DC magnetron sputtering process," Surface and Coatings Technology, vol. 177-178, pp. 434-440, 2004.

[39] S. Veprek, M. G. J. Veprek-Heijman, P. Karvankova, and J. Prochazka, "Different approaches to superhard coatings and nanocomposites," Thin Solid Films, vol. 476, no. 1, pp. 1-29, 2005.

[40] R. F. Bunshah, Handbook of Deposition Technologies for Films and Coatings, Noyes Publications, Park Ridge, Ill, USA, 2nd edition, 1994.

[41] J. W. Lee, S. K. Tien, and Y. C. Kuo, "The effects of pulse frequency and substrate bias to the mechanical properties of CrN coatings deposited by pulsed DC magnetron sputtering," Thin Solid Films, vol. 494, no. 1-2, pp. 161-167, 2006.

[42] W. Herr and E. Broszeit, "The influence of a heat treatment on the microstructure and mechanical properties of sputtered coatings," Surface and Coatings Technology, vol. 97, no. 1-3, pp. 335-340, 1997.

[43] H. Ljungcrantz, L. Hultman, J. E. Sundgren, and L. Karlsson, "Ion induced stress generation in arc-evaporated TiN films," Journal of Applied Physics, vol. 78, no. 2, pp. 832-837, 1995.

[44] M. Ohring, The Materials Science of Thin Films, Academic Press, Boston, Mass, USA, 1993.

[45] X. Chu, S. A. Barnett, M. S. Wong, and W. D. Sproul, "Reactive unbalanced magnetron sputter deposition of polycrystalline TiN/NbN superlattice coatings," Surface and Coatings Technology, vol. 57, no. 1, pp. 13-18, 1993. 

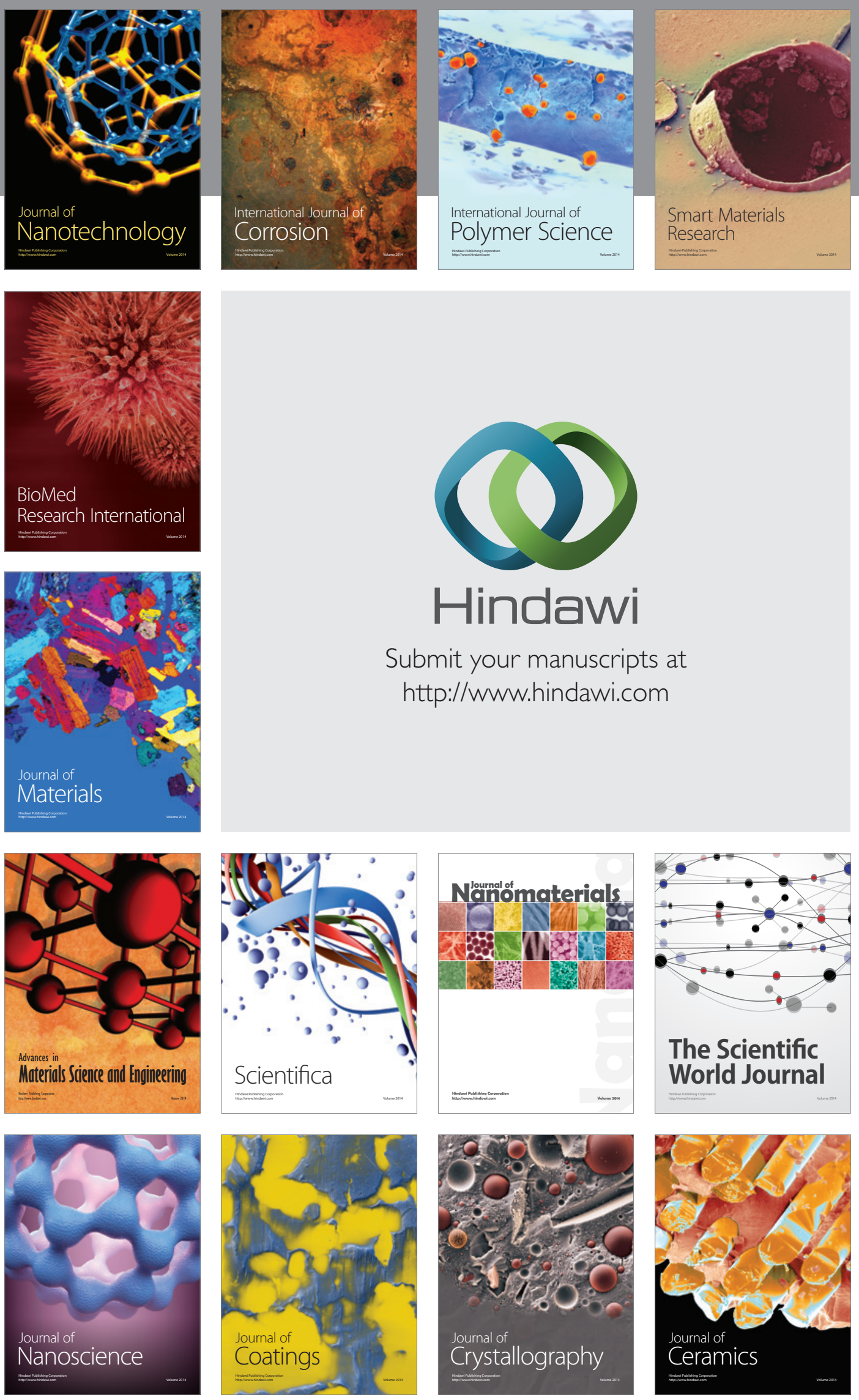

The Scientific World Journal

Submit your manuscripts at

http://www.hindawi.com

\section{World Journal}

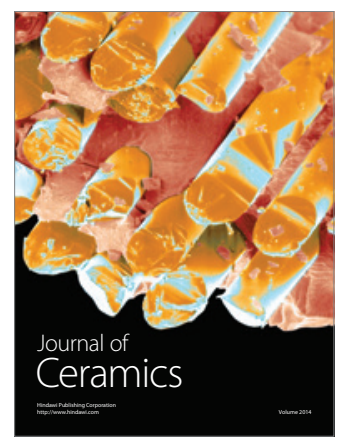

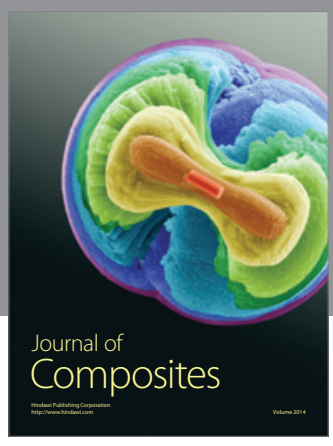
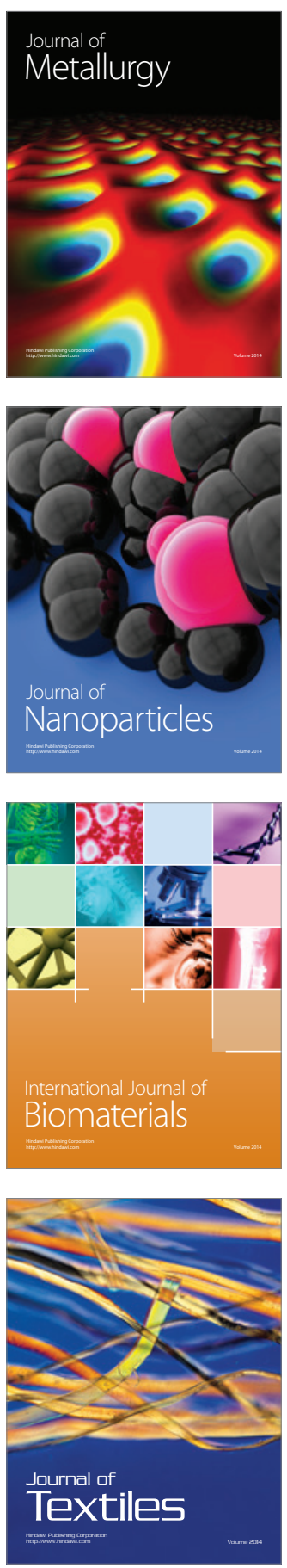